\title{
Semblanza y liderazgo de Omar Dengo: vigencia de su pensamiento
}

\author{
Magdalena Alfaro Rodríguez. \\ Académica de la División de Educología del CIDE,Universidad Nacional \\ Heredia, Costa Rica \\ Marie Claire Vargas Dengo ${ }^{2}$ \\ Académica de la División de Educación Básica del CIDE, Universidad Nacional \\ Heredia, Costa Rica
}

Recibido 29 de noviembre de 2007 • Aprobado 17 de junio de 2008

\begin{abstract}
Resumen. Aspectos de la vida de Omar Dengo delinean su obra y lo definen como figura de connotado liderazgo humanista. Su quehacer docente y compromiso social se reflejan en su acción civilista que trasciende su época y aún hoy es vigente.
\end{abstract}

Palabras clave. Educación, docencia, liderazgo, sociedad costarricense, Omar Dengo.

Abstract. Aspects of the life of Omar Dengo outline and define him as a figure of outstanding humanistic leadership. His pedagogical work and social commitment are reflected in his actions for civilian causes, which transcend his times and continue to be valid today.

Key words. Education, teaching, leadership, Costa Rican society, Omar Dengo.

\section{INTRODUCCIÓN}

Son muchos los autores nacionales que han escrito en torno a Omar Dengo, relatando aspectos de su vida, personalidad y trayectoria, entre otros González (1929), Cortés (1958), Gamboa (1978), Ferrero (1978) y Dengo (2007). Algunos de estos autores, como don Rafael Cortés (1958), profundizan en sus escritos las cualidades de líder que caracterizaron a Omar Dengo, emblemático educador costarricense de la primera mitad del Siglo XX.

El liderazgo de Omar Dengo puede ser visto a la luz de aportes más recientes sobre liderazgo proporcionados por autores como Covey (1997), Bennis (1990), Bennis y Nanas (1985).

Este artículo, estructurado en tres partes, inicia con una semblanza de Omar Dengo, continúa con una descripción de sus dotes de líder, y concluye con un análisis sobre el impacto y la vigencia de su mensaje y su obra en la educación costarricense.

\footnotetext{
Magíster en Educación con énfasis en Docencia Universitaria de la Universidad Nacional. Actualmente, es académica de la División de Educología del CIDE. Correo electrónico: magdar613@ hotmail.com

2 Magíster en Currículum and Instruction, The George Washington University, U.S.A. Actualmente, es académica de la División de Educación Básica del CIDE. Correo electrónico: : marie d claire@yahoo.com
} 


\section{SEMBLANZA}

Omar Dengo, ese "hombre que cernía la cabeza con las águilas, allá en el picacho avizor de lontananzas; y que también arrullaba el amor como las palomas, en el regazo tibio del alero familiar" (González, 1958, p. 5). Así lo describe don Víctor Guardia Quirós al evocarlo con ocasión de su muerte, según lo cita don Luis Felipe González Flores. Con esta descripción apegada de su personalidad hace mención a algunas de las cualidades y características del gran maestro costarricense.

En una casona que era propiedad del Estado, situada frente a la Estación del Atlántico, nació Omar Dengo, el 9 de Marzo de 1888. Su padre, don Manuel Dengo Bertora, ingeniero mecánico graduado de la Universidad de Santo Tomás, participó en la fundación del ferrocarril al Atlántico y fue quien puso la electricidad en San José. Don Manuel Dengo fue un enamorado de la cultura, de los libros de historia, ciencias y filosofía, un hombre fuerte, pero amable y compasivo por los más necesitados. La madre adoptiva de Omar Dengo, Mercedes Guerrero, le inculcó los principios de educación y de rectitud. Desde temprana edad, a lo interno de su hogar se llevaban a cabo tertulias sobre temas sociales, políticos y literarios.

Durante su niñez tuvo pocos amigos, por lo que se acostumbró a la soledad y a carecer de las travesuras comunes en los grupos de niños. En el año 1898, ingresa a la escuela de la niña Filomena García, situada en la Avenida Central, Calles 3 y 5. Su primera maestra fue Rosaura Rodríguez; quien cuenta que el niño Omar llegó deletreando las palabras de un cartel que se utilizaba para enseñar a leer. Mostraba inquietud no sólo intelectual, sino, también, física, pues sentía que se les imponía una gran rigidez y un silencio casi absoluto; cosa que era difícil para él. Por su quebrantada salud, en algunos momentos, debió recibir sus lecciones en la casa de habitación, situada para entonces, en el barrio La merced en San José.

Para este tiempo, se empieza a consolidar la reforma de don Mauro Fernández y los ideales de la 'escuela nueva' tienen efectos e influencia en su formación. En 1901, fue matriculado en el Liceo de Costa Rica, a los doce años de edad. En esta época, recibió las enseñanzas de don Roberto Brenes Mesén y de don Joaquín García Monge, profesores del Liceo, quienes calan hondo en su pensamiento, influyen en su visión de mundo y cuya amistad se mantuvo más allá de su muerte. Se distinguió por sus dotes de orador. En el año 1908, obtiene su bachillerato en Ciencias y Letras.

No obstante, su inclinación por los estudios superiores científicos, que no se impartían en el país, hizo que en 1908 se matriculara en la Escuela de Derecho; en 1911 obtiene el bachillerato en Leyes; sin embargo, no se vio interesado en continuar con la Licenciatura en Derecho; por lo que participa de una pasantía, razón por la cual abandonó los estudios jurídicos. A pesar de esto, esa formación académica le permitió trabajar como secretario en el Juzgado $2^{\circ}$ del Crimen, en la ciudad de San José. Esta experiencia laboral fue muy corta, pero valiosa para comprender los problemas que aquejaban a la niñez y a la juventud. A partir de ese momento, empezó a preocuparse por la delincuencia infantil, convencido muy posteriormente, como él mismo declara en sus escritos, de que el problema social es un problema de educación por excelencia. Domina en él un impulso literario que lo hace participar, férreamente, en diferentes periódicos del país y que lo lleva a fundar un periódico llamado Sanción.

La formación en Derecho, enriquece la calidad de sus escritos para los periódicos de los que formó parte, tales como el periódico El Rayo. Junto con su cercano amigo, Víctor Manuel Obregón, adquieren la maquinaria necesaria para instalar un taller tipográfico denominado "La Comercial", en el que reciben diversos encargos de trabajo con los que pagan la deuda contraída para establecer la imprenta. 
Para estos años se hizo cargo del periódico Cultura (del 8 de Junio al 15 de Agosto de 1910), el cual estaba dirigido a los trabajadores que anhelaban instruirse y progresar. En este periódico colaboraron escritores nacionales como García Monge, José María (Billo) Zeledón, Carmen Lyra y otros. También se reproducían páginas de autores como Tolstoi y Gorki. Durante esta época, conduce campañas para adversar las empresas mineras del Pacífico, las concesiones a la Compañía Frutera y la fabricación de licor por parte del Estado.

En 1912, funda junto con José María Zeledón, Carmen Lyra y otros intelectuales, el Centro de Educación para obreros, denominado 'Germinal', en el cual inicia su experiencia como profesor, y en el que colaboró hasta 1914.

En 1913 ingresa a la asociación cultural Ateneo de Costa Rica, la cual dirige hasta 1918, época en la que se acentúa la influencia que recibiera de don Joaquín García Monge en aspectos humanísticos, especialmente en el americanismo. Influyen, también, en su pensamiento los escritos de Tolstoi, Martí, Sarmiento, Rubén Darío y otros importantes latinoamericanos, como el uruguayo José Enrique Rodó, quien introduce el "arielismo" en Latinoamérica. Omar Dengo coincide con el pensamiento arielista y lo manifiesta en su preocupación por la clase obrera y por los asuntos éticos, políticos e internacionales. Sus inquietudes al respecto fueron publicadas en la Colección Ariel y en varias ediciones del Repertorio Americano, la gran obra cultural de don Joaquín García Monge.

En 1914, al quedar una vacante en el Liceo de Costa Rica, don Roberto Brenes Mesén, le sugiere que se incorpore a este centro. Comienza, entonces, su experiencia en el campo docente como profesor en la Cátedra de Economía Política. Luego fue nombrado profesor de Castellano, Lógica y Debate, experiencia muy importante en su vida, pues al año siguiente se le designa como uno de los profesores competentes para trabajar en una institución orientada por las nuevas concepciones pedagógicas: la Escuela Normal de Costa Rica. Se inicia el curso lectivo en marzo de 1915; en la que trabaja como profesor de Legislación Escolar, Historia de la Educación Extranjera y Nacional, Sociología de la Educación y Lógica y Debate. Más adelante, se le asignó el cargo de disciplinista auxiliar, función posteriormente conocida como inspector.

A finales de 1915 viaja a los Estados Unidos. Allí estudia algunos programas y métodos que pudieran adaptarse a la educación costarricense. Profundiza en el pensamiento de célebres autores de pedagogía, tales como John Dewey y el psicólogo Thorndike, de los que integra el concepto de libertad aplicado a los métodos de pensamiento y acción democrática, que implican la responsabilidad social, la autonomía y la creatividad. Además, ahonda en las prácticas pedagógicas de punta, los aportes de la escuela en Europa y América.

A su regreso a Costa Rica vuelve a la Escuela Normal. En 1917, celebra nupcias con doña María Teresa Obregón Zamora, después de un noviazgo de casi nueve años. De su matrimonio nacieron tres hijos y una hija: Jorge Manuel, Omar, Gabriel y María Eugenia.

La Primera Guerra Mundial (1914-1918) produjo en Omar Dengo un gran impacto tanto en el nivel humano como en el intelectual. Esto coincidió con su inclinación hacia la teosofía, doctrina que conoció tanto por medio de don Roberto Brenes Mesén, como de quien llegara a ser su esposa, María Teresa Obregón Zamora. Esta doctrina tuvo una influencia fundamental en su vida espiritual por su contenido trascendentalista.

Omar Dengo permaneció en la Escuela Normal hasta que pasó la amenaza de que ésta fuera clausurada: uno de los peligros de la dictadura de los Tinoco. Renunció, junto con muchos de los profesores y profesoras, cuando fue destituido su director don Joaquín García Monge, en 1918, por sus adversarios quienes no entendían las corrientes pedagógicas del momento que impulsaba la Escuela Normal. 
Cuando triunfó la Revolución contra Tinoco, en agosto de 1919, en el mes de setiembre, el nuevo Ministro de Instrucción Pública, don Joaquín García Monge, designó a Omar Dengo, director de la Escuela Normal, así como profesor de Pedagogía y Metodología, cargos de desempeñó hasta su muerte.

Además de su labor docente en la Escuela Normal, Omar Dengo vigilaba la conducta dentro y fuera de ese centro educativo, procuraba orientar la vida social de los alumnos y velaba porque la biblioteca y las colecciones de objetos estuvieran en buen estado. También se encargó de dirigir la Revista de Educación, con el propósito de divulgar los aspectos culturales de la institución. Era el brazo derecho del director, don Joaquín García Monge, por lo que sintió la necesidad de ahondar en los estudios pedagógicos y sicológicos. Trabajó en la Escuela Normal hasta 1918, año en que renunció a su cargo. Sin embargo, continuó trabajando en la Escuela República Argentina que era la Escuela de Aplicación de la Escuela Normal.

En 1920, la Secretaría de Educación Pública, aprobó un nuevo plan de estudios propuesto por Omar Dengo. Para este tiempo, se modificó el Reglamento de Becas de la Escuela Normal, y se abrieron más oportunidades para que la gente de escasos recursos pudiera estudiar en esa institución.

En 1922, se realizó en Costa Rica un congreso pedagógico en la Biblioteca Nacional, en el que se analizaron los programas de don Roberto Brenes Mesén, de los cuales el gran defensor fue Omar Dengo, quien se mantuvo en la dirección y en las aulas como un docente lleno de entusiasmo, hasta el día de su muerte.

En 1928, su salud estaba bastante quebrantada y descuidada, en noviembre se agrava y muere el día 18 con mucha paz y fortaleza, en plena juventud, llena de esperanzas, ideales; acompañado por la admiración de todos aquellos que le conocían. Su muerte causó un gran impacto en su país; alumnos y compañeros le acompañaron y sintieron mucho su partida.

\section{LIDERAZGO}

Omar Dengo, no se propuso figurar, en ser o hacerse líder; simplemente se fue conformando como tal, con grandes cualidades que le favorecieron. Lo describe don Luis Felipe González Flores, Subsecretario de Instrucción Pública entre 1914 y 1917, como un hombre con una inteligencia brillante, reflexiva, metódica y rápida en la comprensión de las cosas; un hombre con un carácter humilde que luchó incansablemente por Costa Rica, al lado de los pobres y más necesitados, fascinante y reflexivo, con una formación sólida en principios y valores, quien desde niño contó con influencias importantísimas (González, citado por González, 1958).

Según Bennis (1990, p. 5), "nadie se propone hacerse líder por el solo gusto de serlo, sino más bien para expresarse libre y totalmente", cualidades que, para Covey (1997), son básicas en un liderazgo centrado en principios. De acuerdo con Gardner (1998), algunos elementos de la personalidad son determinantes para el liderazgo, tales como las necesidades personales, la experiencia en los primeros años de vida y la relación con las otras personas. Las habilidades humanas son fundamentales para ejercer un liderazgo efectivo, ya que el líder influye en las demás personas, por tanto, requiere de un buen desarrollo de su inteligencia emocional.

Otros autores, como Mora (2003), también hacen alusión a la personalidad magnética de Omar Dengo, a su brillante inteligencia y a su palabra liberadora. Además, de que era un hombre multifacético y humanista, de la talla de Roberto Brenes Mesén, Joaquín García Monge y otros. Le apasionaba leer; se interesaba por las problemáticas sociales del país y de América Latina. Fue un hombre culto y abierto a las nuevas ideas, no sólo en materia de educación, sino, también, de 
cultura y política. Rodríguez (citado por Mora, 2003), dice que logra "conciliar, admirablemente, el idealismo en los propósitos finales y los recursos prácticos en los procedimientos".

Omar Dengo fue un escritor nato, escribía sobre diferentes temáticas, dentro de las que encontraban especial importancia las necesidades sociales. Parte de su trabajo intelectual consistía en a lectura de textos en varias lenguas, así como a la reflexión de los grandes pensadores de la época, tanto latinoamericanos como europeos. En sus clases se discutían y analizaban obras de Rousseau, Pestalozzi, y Gentile, entre otros. Ponía especial énfasis en la literatura americanista, dentro de la que predominaban autores como Sarmiento, Martí y Simón Bolívar. Para él, la lectura tenía gran importancia en la formación integral de las personas; razón por la cual, trasladó su interés por la literatura de la época a las aulas, pues en sus clases se leía a Tagore, a Gabriela Mistral y a Tolstoi, entre otros.

El maestro Omar Dengo fue un hombre que se acercó a los humildes y se preocupó por ellos, los comprendió y luchó por su bienestar.

El maestro no está en el Olimpo como los dioses; lo encontramos por los caminos de su patria [...] bajo los aleros de la aldea rodeado de campesinos o en las esquinas de la ciudad ayuna de pórticos majestuosos [...]. Dialoga en los caminos y en las calles de la ciudad con el pequeño escolar, con el humilde trabajador, con el campesino de mano firme, con la joven colegial, con el maestro, con el togado, con el reportero cazador de noticia, con la madre de una niña que estudia en su escuela, con el gamonal de pueblo, con todos (Cortés, 1978, p. 128).

Con actitud positiva y creativa, Omar Dengo fue un visionario y un inspirador de quien emanaron frases iluminadas como cuando ante la desatada primera Guerra mundial anhela la paz del mundo y como único camino encuentra que "la educación es la felicidad del mundo" (Cortés, 1978, p. 127). Su espíritu era entusiasta, esperanzado y confiado: "en cuya presencia el corazón del discípulo queda prisionero en la simpatía primero, mientras la mente se abre para comprenderlo y admirarlo en su grandeza humana" (Cortés, p. 131). Acota Cortés que "cuando habla a las muchedumbres, su palabra alada se adueña del entendimiento de todos los que le escuchan y anida en el corazón para sentir, en algún instante, el nacimiento de la luz. Habla para que le entiendan, para que le comprendan, para que los que le escuchan sientan algo nuevo en sus propias existencias". (p. 129)

Omar Dengo fue un líder social, pues conocía bastante bien las necesidades y recursos del país; elementos que relacionaba con la educación, pues consideró que era necesario conocerla para construir una educación acorde con la realidad social y, así, evitar la desvinculación entre la escuela y la realidad. Manifestó sus ideas antiimperialistas en un inicio con cautela, pero algunos años más tarde con firmeza y vehemencia. Según Gardner (citado por Bennis, 1990, p.10): "A los líderes les corresponde un papel significativo en la creación del Estado [...] pueden expresar los valores que mantienen a la sociedad unida. Lo más importante es que pueden concebir y expresar metas que elevan a la gente por encima de los conflictos que despedazan una sociedad, y la unen en busca de objetivos dignos de sus mejores esfuerzos". Algunas de sus prácticas fueron "combatir prejuicios y defender ideales". No creyó en las diferencias de etnia, lo cual demostró en la Escuela Normal cuando dijo que aceptaba con los brazos abiertos a los negros quienes se sintieron acogidos en este centro de estudios, lo cual evidencia que fue "un hombre de conceptos universales; consideraba que el maestro no podía ser indiferente a los problemas de la realidad mundial contemporánea" (González, 1958, p. 113). 
Omar Dengo fue un líder en el campo de la educación. Para él, ésta permite la transformación y el progreso del hombre (González, 1958). Considera a la educación como "el motor principal para la transformación económica y social del país" (González, pp. 120-121). Destaca, en su liderazgo dentro del campo educativo, la pasión con la que trabajó y la forma en que concebía los procesos educativos. Esto lo llevó a luchar por la renovación de la educación costarricense.

Omar Dengo consideró los problemas como retos, era optimista, pues creía que los problemas tienen solución y, de hecho, buscaba resolverlos dispuesto a invertir tiempo y esfuerzo. De acuerdo con González (1929), Omar Dengo:

Pudo encontrar en su mundo interno un mundo más suave y más dulce que le producía emociones de una alegría sublime, inefable, superiores a las mundanas externas, y que venían de compensar desencantos que hubiera experimentado. El misticismo constituyó en Omar un sueño de amor y de fraternidad, un ideal de penetrante subjetivismo. Su paisaje interno se dibujaba con los mismos colores radiosos y asumía mayor intensidad. Omar era un místico de las tendencias preponderantemente sociales de nuestra época. (p. 33)

Su preocupación por los problemas sociales y su interés por los problemas de la niñez, generan su vocación por la educación. Los ideales políticos se despiertan en Omar Dengo en la época de su adolescencia, expresados en ideas de justicia social y de amor al prójimo. La juventud de Omar Dengo está signada por su preocupación social lo inclinó a participar activamente en el movimiento político denominado 'anarquismo'. Era un joven curioso, emotivo, que se interesó profundamente por sus derechos y obligaciones como miembro de una sociedad organizada. Luchó por renovar la política en contra de la corrupción. Creyó en las capacidades de los costarricenses, pero luchó contra el conformismo. Antiimperialista, estaba "resuelto a contagiar a los apáticos y de 'patriotismo flojo'; desde las aulas hizo ver a sus alumnos cuál era la situación creada por los hombres entonces en el poder" (González, 1958, p. 42).

Omar Dengo participó en varias políticas. En 1910, luchó contra las compañías mineras por el maltrato y los bajos salarios de los trabajadores. Además, criticó, muy fuerte, la fábrica de licor, diciendo que "lo único que puede salvarnos es la cultura del pueblo, pues si somos cultos podremos explotar, adecuadamente, las riquezas del suelo y conquistar la independencia económica y política” (Dengo, citado por González, 1958, pp. 53-54). También luchó contra la compañía United Fruit Company; en 1926, fue invitado a exponer sus ideas sobre los contratos bananeros adquiridos y propuestos al Congreso; sobre lo que hace un análisis de corte "espiritual [...], lo que significa para un hombre de principios sanos, el tener en su territorio una fuerza de conquista que intervendrá hasta en sus asuntos políticos, y decidirá en ellos como lo prueba el reconocimiento de Adolfo Díaz de Nicaragua [...]" (González, p. 53).

Algunos datos importantes que revelan las luchas que dio con su pensamiento en contra del partido civilista, se publicaron en el periódico El rayo en forma de artículos y de caricaturas, de las cuales se desconoce el autor.

Omar Dengo practicó, firmemente, la fuerza de la sinceridad, de la cual anota en su escrito "Por la sinceridad", que, "pueden triunfar el Arte y la Democracia, pero mientras no triunfe la Sinceridad, todo lo que se pretende destruir continuará imperturbablemente su curso y seguirán muriendo bajo el peso de las inequidades los hombres que nazcan para combatirlas (Dengo, citado por Dengo, 2007, p. 90). Cabe resaltar que Omar Dengo creía firmemente en la fuerza creativa del joven, en sus capacidades y su vitalidad para provocar cambios; de los que decía: "Jóvenes, ahora 
a vivir, eso es lo importante. Ahora a realizar una obra en nuestra Patria, a preparar los himnos de la renovación que viene" (Cortés, 1978, p. 155). También consideraba que los jóvenes deben indagar el pensamiento de los que los han antecedido, para aprender de sus méritos. Estas ideas eran parte de sus sueños e ideales.

Omar Dengo se interesó por la sociología y la psicología como disciplinas que forman parte de los procesos educativos y como fundamento en la determinación de los principios y métodos de la educación. En 1920, recalcó que a los maestros debe dárseles una intensa formación basada en el conocimiento de sociología educativa, pues veía una desvinculación muy marcada entre lo que se enseñaba y la vida social (González, 1958).

Para Omar Dengo, la escuela es una sociedad, la sociedad es portadora de cultura y es la escuela de la vida: "no debemos olvidar que la escuela es un ambiente, es una sociedad en pequeño en que debe educarse para la vida, pues su material humano es un material social y, por tanto, la escuela debe abandonar la posición de isla y tratar de construir el puente hacia la sociedad para que los educandos, en ambos ambientes pisen terrenos" (Dengo, citado por González, 1958, p. 89). Según González, la escuela que encontró Omar Dengo, era todo lo contrario. "Era una escuela formal, muerta: era necesario vitalizarla, desformalizarla, que dejara de ser únicamente la máquina de embutir conocimientos teóricos" (González, 1958, p. 89). "Don Omar quería que su escuela se ocupara de la vida colectiva. No quería una escuela sumisa y silenciosa ante los problemas que embargaban al país" (González, 1958, p. 92).

Crítico de la educación y de la enseñanza, Omar Dengo se interesó por los problemas educativos, sobre los que no sólo escribió, sino que también propuso cambios importantes para combatir la forma sistemática de la rutina y el mecanicismo en la enseñanza "[...] en la escuela debemos aprender para la vida y para adquirir poder; no para cumplir programas ni para rendir exámenes" (Dengo, citado por González, 1958, p. 116). Dio un valor importante al 'diario de clase' como medio para percatarse de las diferentes situaciones subjetivas de cada lección, los avances, los intereses y las necesidades de los alumnos, en función de una educación más práctica que retomara aspectos de ciudadanía para poder educar y orientar a los alumnos en una actitud responsable frente a las necesidades del país.

Visionario de la importancia del aprendizaje en la vida de las personas, manifestó que "la escuela debe ser instrumento de creación del porvenir, pero debe tener aptitud para el trabajo que se le confía y debe ser como instrumento, usado conscientemente" (Dengo, citado por Cortés, 1978, p. 178). "Para él, los conocimientos debían ser agentes de autonomía espiritual" (Chaves, Guillén, Jiménez, Martínez, Sebiani, Suárez, 1988, p. 27).

En una carta Omar Dengo (citado por González 1958) expresó:

Todas las mañanas, cuando visito las escuelas en que recojo el material para mis estudios de estas largas noches, cuando converso acerca de propósitos y procedimientos con las maestras, cuando acaricio a los niños, cuando observo el material de enseñanza, y recorro las bibliotecas, se me llena el alma de una vigorosa esperanza, de un hondo idealismo, de una profunda fe en la obra del maestro, y sueño que estamos haciendo esa obra, juntos, en nuestra escuela, con un espíritu nuevo en el paso, nuevo aunque eterno, en la educación, fraternalmente, como en Shanti Niketan bajo el arbolado de amor que nuestro corazón sabrá tener sobre la inquietud de la generación que nos espera. (s. p.)

Estas palabras de Omar Dengo revelan la profundidad y trascendencia de su pensamiento, con lo cual se logra comprender el espíritu renovador y el poder transformador de la obra educativa. 


\section{LIDERAZGO CENTRADO EN PRINCIPIOS}

El liderazgo centrado en principios, aportado por Covey (1997), indica que estos líderes, tienen las siguientes características:

Aprenden continuamente: Son educados constantemente por sus propias experiencias. Leen, buscan la forma de capacitarse [...], escuchan a los demás [...] son curiosos [...]. Tienen vocación por servir: consideran la vida como una misión no como una carrera [...]. Todas las mañanas, en efecto, se 'atan al yugo' y se colocan los arneses del servicio, pensando en los demás [...]. Irradian energía positiva [...]. Creen en los demás: Las personas basadas en principios no sobre reaccionan ante las conductas negativas, las críticas ni las debilidades humanas, creen en la potencialidad invisible de todos los demás [...]. Dirigen sus vidas de forma equilibrada: leen los mejores libros y revistas y se mantiene al día respecto al curso de los negocios y acontecimientos. Son socialmente activos [...]. Sus acciones y actitudes son adecuadas a cada situación: equilibradas, mesuradas, moderadas y prudentes [...]. Son sinérgicos: la sinergia es el estado en el que el todo es superior a la suma de las partes [...], son catalizadoras de cambio [...] mejoran casi todas las situaciones en las que intervienen [...], trabajan tan duro como inteligentemente [...]. Se ejercitan para la auto renovación: ejercitan sus mentes leyendo, resolviendo problemas creativos, escribiendo y observando [...]. Ven la vida como una aventura: disfrutan de la vida [...], su seguridad emana de su interior y no de afuera. (pp. 37-44)

Los principios acotados por Covey, se ajustan a la forma de vida de Omar Dengo, por lo que se podría afirmar que en esencia fue un líder centrado en principios. Un análisis comparativo de los rasgos característicos del liderazgo, centrado en principios, con las cualidades que durante su vida desplegó Omar Dengo, conduce a afirmar que dichas cualidades es lo que le han dado permanencia no sólo a su recuerdo, sino, también, a su ejemplo y a su pensamiento casi un siglo después.

\section{OTRAS FORMAS DE LIDERAZGO}

Bennis y Nanas (1985), destacan que dentro de las estrategias para ejercer un liderazgo eficaz, está el reconocimiento por parte del líder de la importancia de la participación para el aprendizaje, es decir, que el líder debe estar profundamente involucrado en los procesos para poder ofrecer aportes a su desarrollo.

Por otro lado, Gardner (1998), se refiere al liderazgo "directo", el cual se da mediante la relación de historias y su encarnación. Éste es más tumultuoso y arriesgado, pero, a corto plazo, puede ser más eficiente y más eficaz. A principios del siglo XX, Omar Dengo, por ejemplo, junto a otros jóvenes, quienes tenían fuertes deseos de renovación, de cambio, de rompimiento contra las estructuras, estuvo inmerso en las luchas por combatir al candidato civilista don Rafael Iglesias, a quien consideraba un tirano que debía desaparecer. Se dieron, entonces, luchas cívicas mediante el periódico La Vanguardia, el cual fundó y se destacó como un órgano juvenil que apoyaría a don Ricardo Jiménez Oreamuno en su campaña política.

Kouzes y Posner (1999) afirman que el liderazgo es "el arte de influir sobre la gente para que trabaje con entusiasmo en la consecución de objetivos en pro del bien común” (p. 21). Para Bennis 
(1990, pp. 32-33), "la integridad es la base de la confianza, la cual no es tanto un ingrediente del liderazgo como un producto de éste. Es la cualidad que no se puede adquirir sino que tiene que ganarse". La curiosidad y la audacia, también son ingredientes básicos del liderazgo. "El líder se interesa por todo, quiere aprender todo lo que pueda, está dispuesto a arriesgarse, a experimentar, a ensayar cosas nuevas" (Bennis, p. 33). Este autor expresa que "un ingrediente básico del liderazgo es la pasión subyacente por las promesas de la vida, combinada con una pasión muy particular por la vocación, profesión, línea de conducta. El líder ama lo que hace y le encanta hacerlo" (p. 30).

Según Bennis (1990, p. 163), "la cualidad que mejor define al líder es su capacidad de crear y realizar una visión”. Esta cualidad, se puede decir, fue expresada por Omar Dengo como portador de cambios y transformaciones sociales, pues alcanzó a ver en la educación la fuente de transformación de la nación y aspiró a que "la educación para los costarricenses, debe ser el instrumento que prepara al ciudadano para contribuir inteligentemente a la solución de los problemas sociales del país" (Cortés, 1978, p. 137). Alcanzó a vislumbrar hacia el futuro una transformación hacia niveles superiores cimentados en "la formación de una elevada conciencia nacional: [...] si para el futuro se pretende construir y construir en firme, sacar los tesoros de fuerzas morales inactivos en el fondo del alma costarricense, en la hora propicia en que el mundo todo se transforma al impulso de un formidable designio cósmico" (Dengo, citado por Cortés, p. 137).

Omar Dengo manifiesta rasgos de líder 'transformativo', ya que promueve el cambio, se acerca a los humildes y medita sobre la situación de aquellos hombres y mujeres, los comprende y lucha por su bienestar. En palabras de Cortés (1978, p. 163), "Omar era un líder de elevada jerarquía espiritual. Si lo hubiera querido habría sido un caudillo". En las diferentes luchas sociales que Omar Dengo sostuvo, muestra características propias de un líder transformador; toma el parecer de sus seguidores para trascender su interés por el bien del grupo y de la organización; se preocupa más por las metas de largo plazo y tiene gran conciencia de lo que es importante. Movido por su impulso de renovador social, cree necesario insistir para lograr la colaboración de los ciudadanos y hacer viable la transformación de la escuela (González, 1958).

\section{IMPACTO DEL LIDERAZGO DE OMAR DENGO EN LA EDUCACIÓN COSTARRICENSE: VIGENCIA DE SU PENSAMIENTO}

El principal aporte que lega Omar Dengo a los educadores costarricenses, impacta de manera contundente la visión de la educación y el concepto de educador de su época, lo cual trasciende hasta hoy, en circunstancias sociohistóricas diferentes, es tan vigente como lo fue entonces, pues su mensaje resulta pertinente para nuestro momento.

Así como trabajó por la renovación de la escuela costarricense, Omar Dengo se preocupó por la solución de nuestros problemas educativos, visualizando que está condicionada por la realidad política, económica y social del país, así como por la realidad psicológica del educando (González, 1958). El mensaje fundamental de Omar Dengo es que el maestro no puede ser indiferente a los problemas de la realidad mundial contemporánea (González, 1953). Por tanto, "el maestro más que ningún otro profesional debe tener una buena cultura general y ampliamente humana" (González, 1958, p. 111).

Es valiosa la revisión y la revaloración de este mensaje para quienes ejercen y administran la docencia, para las actuales escuelas de formación docente y para quienes se forman y se formarán como docentes y administradores de la educación, educadores costarricenses del Siglo XXI, pues como señala el mismo Omar Dengo "el comienzo de todo debe estar en darle a la escuela el maestro 
que necesita, respaldado por una política pedagógica que determine claras direcciones, en los fines de la labor de la escuela y encare sus problemas" (Dengo, citado por González, 1958, p. 90).

La educación es, para Omar Dengo, la herramienta al alcance del hombre para realizar cambios sociales: "En todas las épocas, pero sobre todo en la presente, el problema social es problema de educación, por excelencia. Y ello no es la obra exclusiva de las necesidades sociales y de la escuela misma, sino además el requerimiento estricto de las disciplinas que interpretan la naturaleza y el valor de las necesidades" (Dengo, citado por Cortés, 1978, p. 137). Concibe que la educación debe cumplir una finalidad colectiva desde la escuela y las aulas, hacia el objetivo de la vida de cada quien: "Es decir, a preparar al hombre para el cumplimiento de sus deberes en el campo que cada cual debe cultivar particularmente y prepararlo para la siembra, el cultivo y la recolección, en el inmenso lote de actividades y aspiraciones que al conjunto como conjunto le corresponde" (Dengo citado por Cortés, p. 136).

Para Omar Dengo, la educación del pueblo era fundamental en el progreso del país. Por eso, creía firmemente en la necesidad de fortalecer la educación y las escuelas de la nación: "economizar en escuelas es economizar en civilización y ningún pueblo de la tierra tiene derecho a hacerlo. Gastar pródigamente en educación, no es una cuestión de finanzas, sino una cuestión de honor, de decoro nacional" (Dengo, citado por Gamboa, 1971, p. 41). Consideraba que economizar en escuelas es economizar en civilización, pues a través de la educación es la única forma en que las personas pueden desarrollarse y a su vez transformar la sociedad, decía que "el comienzo de todo debe estar en darle a la escuela el maestro que necesita, respaldado por la política pedagógica que determine claras direcciones, en los fines de la labor de la escuela, y encare sus problemas" (Dengo, citado por González 1958, p. 90). Según Gardner (1998) dentro de las características del liderazgo eficaz está el reconocimiento de los problemas, aspecto que logró entender muy bien Omar Dengo.

El pensamiento de Omar Dengo acerca de la enseñanza va orientado a la comprensión de su función en el ámbito social y para las generaciones futuras. Ejemplarizó que el maestro debe ser dinámico y progresivo, estar dispuesto a crear la escuela no sólo en la aulas, sino, también, fuera de ellas: "no hay educación posible si no está destinada al cumplimiento de los deberes humanos, en la más comprensiva acepción de la palabra" (Dengo, citado por González, 1929, p. 53).

Cabe afirmar que Omar Dengo fue capaz de esculpir su pensamiento en la mente de sus alumnos y en la de todos los costarricenses que se han acercado a su obra. El poder transformador de su palabra resonó en el interior de quienes tuvieron la dicha de escucharlo y dialogar con él. "Era tan majestuoso su pensamiento, tan encendida y luminosa su palabra, tan profunda su fe en el porvenir, tan delicada honda su ternura para comprender a los niños, tan respetuosa y diáfana su relación con los jóvenes, tan activa su beligerancia de maestro en relación con los destinos del país y en ellos los de la educación [...]" (Cortés, 1978, p. 127). Así lo evoca don Rafael Cortés intentando acercarlo a nosotros. Y, desde su recuerdo viviente nos lo presenta, para mantener presente su legado y vigente su mensaje, con "su figura cordial y la excelencia del espíritu que iluminó con su vida y sus pensamientos los horizontes de la Escuela Costarricense" (Cortés, p. 127).

¿Por qué es aún vigente su pensamiento? ¿Qué deja Omar Dengo a la posteridad?, pregunta Emma Gamboa (1978), a lo que ella misma responde:

Lo más hondo de su obra es imponderable porque es tránsito de espíritu a espíritu. La entrega diaria a un magisterio directo le priva el retiro necesario para escribir la obra grande y concentrada que su talento puede producir. Los escritos y discursos suyos recogidos en obra póstuma, son parte mínima de su trabajo abundante y profundo. La fecundidad de su palabra cargada de mensaje se advierte, sin embargo, en esos escritos 
y deja simiente en quienes le buscan con inteligencia y corazón abierto. Omar Dengo figura hoy en la galería de los Beneméritos de los órdenes de su vida: en el aula humilde, en la cátedra superior, en el periódico, en el hogar y en plaza pública; maestro de un pueblo y maestro de maestros" (Gamboa, 1978, p. 122).

Su liderazgo ha tenido tal impacto en la sociedad costarricense que la estatua de su figura nos recibe al ingresar en diferentes instituciones del país, tal es el caso, de la Facultad de Educación de la Universidad de Costa Rica, y de la Sede Central de la Universidad Nacional, llamada, precisamente, "Campus Omar Dengo". "Su proyección más honda del acto educativo como un supremo magisterio de dación espiritual hacia el alumno, todo dentro de un proyecto que sirve para formar el intelecto" (UNA, 1961). Reflejo de su pensamiento transformador, semblanza de su figura y manifestación de su espíritu vivo es el legado que preserva la Universidad Nacional desde su creación y hoy da vigencia en su misión humanista al accionar social en la sociedad costarricense.

\section{REFERENCIAS BIBLIOGRÁFICAS}

Bennis, W. (1990). Cómo llegar ser líder. Bogotá, Colombia: Norma.

Bennis, W. \& Nanas, B. (1985). Las cuatro claves del liderazgo eficaz. Bogotá, Colombia: Norma.

Cortés, R. (1978). El pensamiento de Omar Dengo en la educación costarricense. En Ferrero, A., Rodríguez, C., Sáenz, C., Gamboa, E., Cortés, R. (1978). Omar Dengo visto por cinco de sus discípulos. San José: Oficina de Publicaciones Universidad de Costa Rica.

Costa Rica. Ministerio de Educación Pública. (1959). Homenaje a Omar Dengo. San José, Costa Rica: Publicaciones del MEP.

Covey, S. (1997). El liderazgo centrado en principios. Barcelona, España: Paidós.

Chaves, A.; Guillén, C.; Jiménez, L.; Martínez, E.; Sebiani, J. C. \& Suárez, J.D. (1988). Filosofía de la Educación y Omar Dengo. Escuela de Estudios Generales de la Universidad de Costa Rica, San José, Costa Rica: Publicaciones de la UCR.

Dengo, O. (1961). Omar Dengo: Escritos y discursos. Editora: M. E. Dengo. San José, Costa Rica: Imprenta Lehmann.

Dengo, O. (2007). Omar Dengo: Escritos y discursos. Editora: M. E. Dengo. Heredia, Costa Rica: EUNA.

Ferrero, A., Rodríguez, C., Sáenz, C., Gamboa, E. \& Cortés, R. (1978). Omar Dengo visto por cinco de sus discípulos. San José, Costa Rica: Oficina de Publicaciones de la UCR.

Gardner, H. (1998). Mentes líderes. Buenos Aires, Argentina: Paidós. 
Gobernabilidad. (2006). Tipos de liderazgo. Recuperado el 10 de mayo, 2006, de http://www. gobernabilidad.cl/modules.php?name=News\&file=article $\&$ sid $=532$

González, M. (1958). Aspectos biográficos y bibliográficos de Omar Dengo. Tesis presentada para optar por el grado de Licenciado en Filosofía y Letras. San José, Costa Rica.

González, L. (1929). Omar Dengo. Estudio de su personalidad. San José, Costa Rica: Imprenta Nacional.

Kouzes, J. \& Posner, B. (1999). Taller. El desafío del liderazgo. New Jersey, United States: Wiley, John \& Sons.

Monografías.com. (2006) Liderazgo.Recuperado el 15 de mayo,2006, de http://www.jeanespinosa@ hotmail.com

Mora, S. M. (2003, 23 de noviembre). Omar Dengo, constructor del porvenir. La Nación. p. 8. Suplemento Áncora.

Salas, J. (1928). Omar Dengo. Repertorio Americano, Vol. 17, 111, 4.

Universidad Nacional. (1961). Selección de escritos de Omar Dengo. Heredia, Costa Rica: Autor. 


\section{ANEXO. OMAR DENGO}

Era el Maestro

de singular grandeza:

alas en los hombros,

y en la frente,

luz y belleza.

Era de los bravos

y era de los grandes;

parecía un cóndor

que agitara sus alas

por encima de los altos

picachos de los Andes.

Era bolivarísimo

y el Príncipe

de nuestros oradores...

su palabra fecunda tenía

luz de antorcha,

resplandores de aurora...

era para el corazón

como un hermano.

El avivó en la Escuela Normal

el "fuego sagrado"

y lo que Wells llamó un día

la llama inmortal.

Era de los buenos

y era de los nobles.

amó la justicia,

el Bien, la libertad.

al mal supo darle

terribles mandobles...

don quijote viviente,

con su adarga y su lanza

combatió la injusticia

y encendió en muchas almas

un fulgor de esperanza.

Amó y fue muy amado; por eso en su ausencia todos hemos llorado. sereno ante la muerte tuvo estoicismo

de Sócrates

y con sus seres amados, y sereno y triunfante,

con belleza suprema, con valor y heroísmo después de haber luchado, después de haber vivido una vida gloriosa dejó su noble escuela, dejó su amado hogar, y como la mariposa al romper el capullo, voló hacia las regiones donde los inmortales con su luz estelar, con su bien y su amor, conducen nuestros pasos hacia un palmo de vida más noble y superior.

Todos en él miramos la presencia del genio. su voz y su palabra su virtud y su ciencia, su filosofía en las almas dejaban como una melodía.

Hoy lloramos su ausencia y pensamos que la Patria en los cielos ya tiene un arcángel que velacon la espada en la mano, con la luz de sus ojos y su voz inmortalpor su Gloria y su Bien.

Él ha muerto con grandeza y honor; sin odios, sin rencores, pero con un grande amor por todas las cosas bellas que él en la vida supo amar tanto. enjuguemos el llanto, y en el corazón guardemos su recuerdo, su nombre bien amado, que es para nosotros como una luminosa y suprema lección.

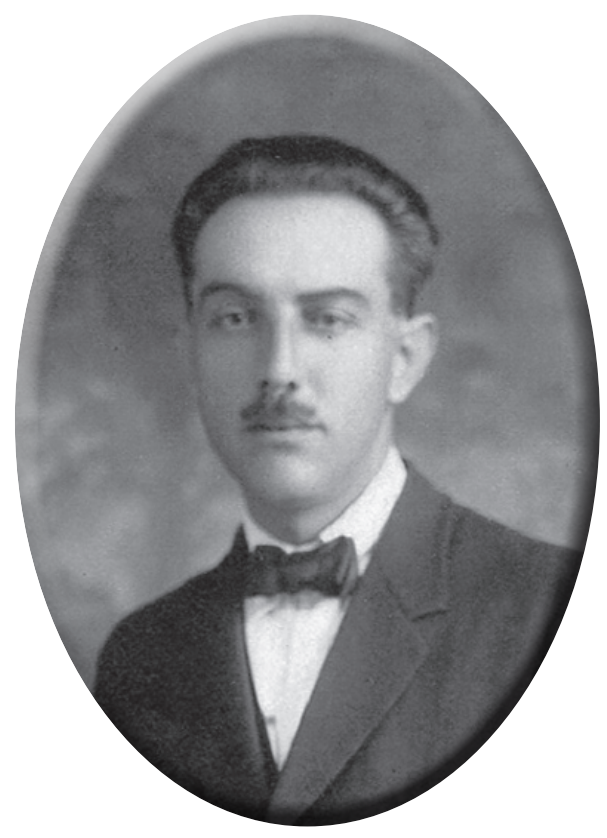

